\title{
A Comparative Study of PI and IP Controllers for Field Oriented Control of Three Phase Induction Motor
}

\author{
Fatma H. Faris ${ }^{1}$, Abdulrahim Thiab Humod ${ }^{2}$, Mohammad Najm Abdullah ${ }^{3}$ \\ 1,2Electrical Engineering Dep., University Of Technology, Baghdad, Iraq. \\ ${ }^{3}$ Computer Engineering Dep.,University Of Technology, Baghdad, Iraq. \\ fatmahf2000@yahoo.com, abdulalrahimhumod@yahoo.com,mustafamna@hotmail.com
}

\begin{abstract}
In this paper, Field Oriented Control (FOC) of 3-phase induction motor is controlled by using (PI) and (I-P). These controllers are established with the help of MATLAB/SIMULINK. The gains value obtained by the trial and error method of PIcontroller and Particle Swarm Optimization (PSO) technique is used in this paper for designing I-P controllers that give better performance. PSO technique was proposed to tune the optimal gains of I-P controller and state feedback gains. A comparison between two controllers is presented. From simulation results, the advantages and disadvantages of both controllers are investigated to explain the characteristic of the two methods. The operation perforamcnes of the two proposed controller systems have been examined in terms of the motor torque, current ripples and momentary responses to load toque variants.
\end{abstract}

Index Terms - Field Oriented Control, PI Controller, I-P-PSO based Controller, induction Motor.

\section{INTRODUCTION}

Induction motors are rocky, cheap to create and easy to keep high reliability, simple and high efficiencies. They can be run at a approximately constant speed from zero to full load.The control of induction motor drives covers a extensive and essential subject, and the technology has additional progressive in recent years. The control of AC drives in general is largely more difficult than of DC drives; this complication increases greatly if high performance is demanded. The main reasons for this complication are the requirement for variable frequency; harmonically optimum converter power supplies [1].

There are several diverse ways to drive an induction motor. The main variances between them are the motor's performance, the feasibility and cost in its real application.

IM control techniques can be divided into scalar and vector control. The scalar control is the simplest control method in which, the motor speed is controlled by both magnitude and frequency of the supply voltages. The scalar control of IM is not suitable for high dynamic performance. In vector control not only magnitude and frequency of the supply voltages are controlled, but also the magnitude and angle of the space vector .

The first vector control method of induction motor was Field Oriented Control (FOC) presented by K. Hasse (Indirect FOC) and F. Blaschke (Direct FOC) in early of 1970s, second vector control method of induction motor was Direct Torque Control (DTC) was first introduced by Takahashi in 1986. $[2,3]$

Many different lessons have been advanced to discover diverse solutions for induction motor control taking the features of accuracy, fast torque response and decline of the complication of the presented algorithms and techniques. 
Fadhil A. Hassan, 2010 [4] proposed the FOC strategy. Rotor flux, unit vector, and electromagnetic torque valuation are considered by using Digital Signal Processing and Artificial Neural Network to guess the flux, unit vector, and electromagnetic torque to decrease the hardware difficulty and the Electromagnetic Interfering (EMI) influence.

Dr.Abdulrahim Thiab Humod, et al., 2016 [5] presents a comparison between two famous control strategies for induction motors: Field Oriented Control (FOC) and Direct Torque Control (DTC).

Pabitra Kumar Behera1, et al., 2014 [6] implemented of scalar \& vector control of three phase induction motor drives.

Dr.Abdulrahim Thiab Humod [7] presents Particle Swarm Optimization technique for designing fractional order PI controllers that give better performance than their integer order counterparts for field oriented control (FOC) of an three phase induction motor.

The contribution of this work is to overcome the problems of the conventional PI controller, such as the high starting overshoot in speed, sensitivity to controller gains and sluggish response due to sudden change in load torque by the replacement of PI controller by Integral plus Proportional (IP) controller.

\section{VECTOR CONTROL OF (IM)}

Vector control is recognized based on relations in dynamics state; both magnitude and frequency, immediate position of voltage, current and flux linkage space vector are controlled. Most prevalent vector control approaches are (FOC) and ( DTC ).

\section{A. FIELD ORIENTED CONTROL}

Vector or Field-Oriented Control (FOC), permits a squirrel-cage induction motor to stand driven with high dynamic performance. It transforms the dynamic structure of the A.C motor into that of separately excited D.C motor $[2,3]$. For D.C motor, the field flux is proportionate with the field current, if the field presumed to be constant and self-governing of armature current, the armature current provides direct control torque, so that:

$$
T_{e} \propto I_{a}
$$

With the induction motor transformed to d-q plane, it looks like a separately excited D.C motor. The (FOC) technique decouples the two components of stator current; one providing the air-gap flux, and the other producing the torque. These current components afford independent control of flux and torque and the characteristic is linear. These components are transferred back to the stator casing afore feeding back to the rotor. The two components are d-axis $i_{d s}^{S}$ analogues to field current $I_{f}$, and q-axis $i_{q s}^{S}$ is analogues to armature current $I_{a}$ of the separately excited D.C motor. This strategy can be implemented by align the rotor flux vector along the d-axis of the stationary frame as shown by the phasor diagram in Fig.1.

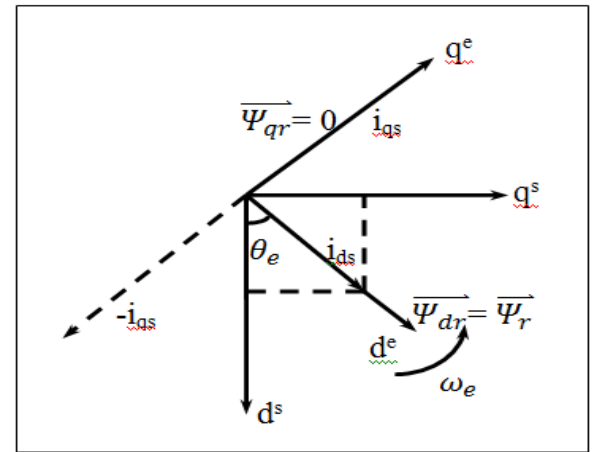

FIG. 1 . PHASOR DIAGRAM OF ROTOR FLUX ORIENTATION 
The fundamentals of vector control implementation can be described in Fig. 2, where the motor model is existing in a synchronously rotating mention casing, the voltage-fed SPWM inverter produces three-phase voltages $\left(v_{a}, v_{b}, v_{c}\right)$ according to the reference command voltages $\left(v_{a}^{*}, v_{b}^{*}, v_{c}^{*}\right)$ the flux component of stator current $\left(i_{d s}^{s^{*}}\right)$ and the torque component of the stator current $\left(i_{q s}^{s^{*}}\right)$ is used as a control signals to the system, which are inversely transformed to three-phase reference currents ( $\left.i_{a}^{*}, i_{b}^{*}, i_{c}^{*}\right)$, and then transferred to three-phase voltages $\left(v_{a}^{*}, v_{b}^{*}, v_{c}^{*}\right)$ through (PI) controller. The vector control FOC can be implemented by either direct or indirect method, these techniques are diverse basically by how the unit vector $\left(\cos \theta_{e}\right.$ and $\left.\sin \theta_{e}\right)$ is estimated for controller $[2,3,8]$.

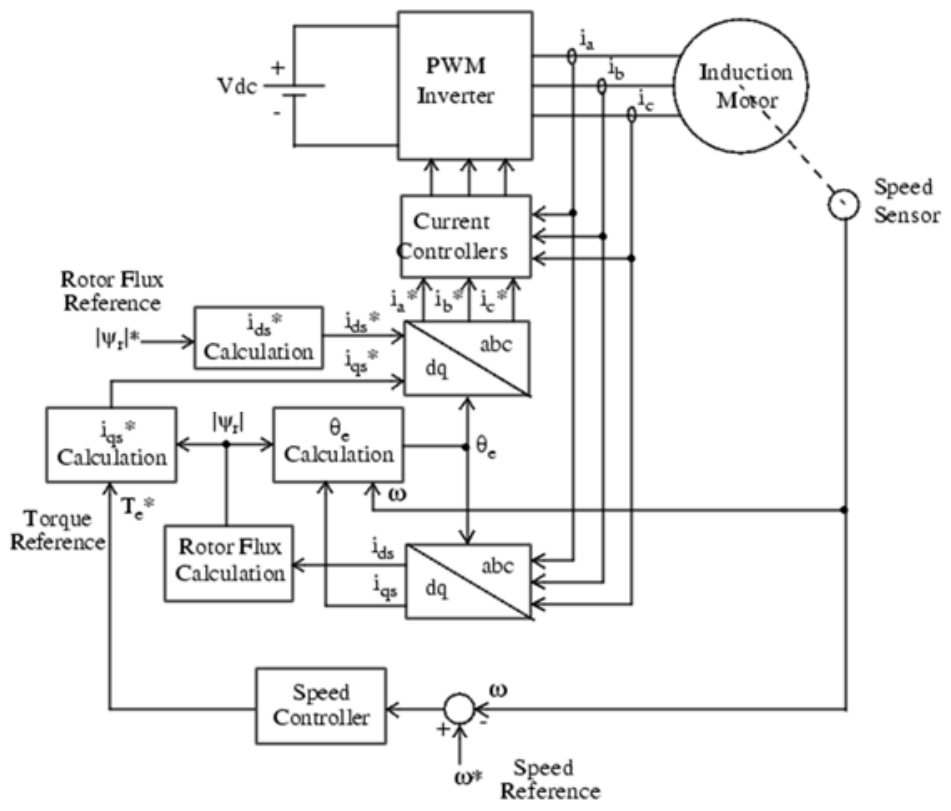

FIG. 2 . FIELD ORIENTED VECTOR CONTROL

\section{B. FLUX VECTOR ESTIMATION}

There are two commonly methods of flux estimation; voltage model, and current model. The first one has solid performance in high speed regions but not in low speeds. Whereas, the second method has an accepted performance in both low and high speeds [1].

The current model depends on the main rotor equations in the two axes stationary frame $\mathrm{d}^{\mathrm{s}}-\mathrm{q}^{\mathrm{s}}$, superscript "s" referred to stationary frame quantities:

$$
\begin{aligned}
& R_{r} i_{q r}{ }^{s}+\frac{d \Psi_{q r}{ }^{s}}{d t}-\omega_{r} \Psi_{d r}{ }^{s}=0 \\
& R_{r} i_{d r}{ }^{s}+\frac{d \Psi_{d r}{ }^{s}}{d t}+\omega_{r} \Psi_{q r}{ }^{s}=0
\end{aligned}
$$

Adding terms $\left(L_{m} R_{r} / L_{r}\right) i_{d s}^{s}$ and $\left(L_{m} R_{r} / L_{r}\right) i_{q s}^{S}$ and simplifying, we get:

$$
\begin{aligned}
& \Psi_{q r}^{S}=\int\left[\frac{L m}{T r} i_{q r}^{S}+\omega_{r} \Psi_{d r}^{S}-\frac{\Psi_{q r}^{S}}{T r}\right] \\
& \Psi_{d r}^{S}=\int\left[\frac{L m}{T r} i_{d r}^{S}-\omega_{r} \Psi_{q r}^{S}-\frac{\Psi_{d r}^{S}}{T r}\right]
\end{aligned}
$$

Where: $\operatorname{Tr}=\frac{L r}{R r}$ is the rotor time constant.

Equations $(4 \& 5)$ give rotor fluxes as a function of stator currents and speed. Therefore, knowing these signals, the rotor flux and agreeing unit vector $\left(\cos \theta_{e}\right.$ and $\left.\sin \theta_{e}\right)$ can be estimated by to implement the following equations: $[2,33]$ 


$$
\left.\begin{array}{c}
\overrightarrow{\Psi_{r}}=\sqrt{\Psi_{q r}^{s^{2}}+\Psi_{d r}^{s^{2}}} \\
\Psi_{q r}^{s}=\overrightarrow{\Psi_{r}} \sin \theta_{e} \\
\Psi_{d r}^{s}=\overrightarrow{\Psi_{r}} \cos \theta_{e} \\
\text { Or: } \sin \theta_{e}=\frac{\Psi_{q r}^{s}}{\overrightarrow{\Psi_{r}}} \\
\cos \theta_{e}=\frac{\Psi_{d r}^{s}}{\overrightarrow{\Psi_{r}}}
\end{array}\right\}
$$

Flux estimation by the current model necessitates a speed encoder, but the advantage is that the drive action can be extended down to low and nil speed. It's important to mention, that the input signals to the estimator ( $i_{q s}^{S}$ and $i_{d s}^{S}$ ) must be filtered by a low pass filter stage. The simulation of the current model estimator can be shown in Fig.3.

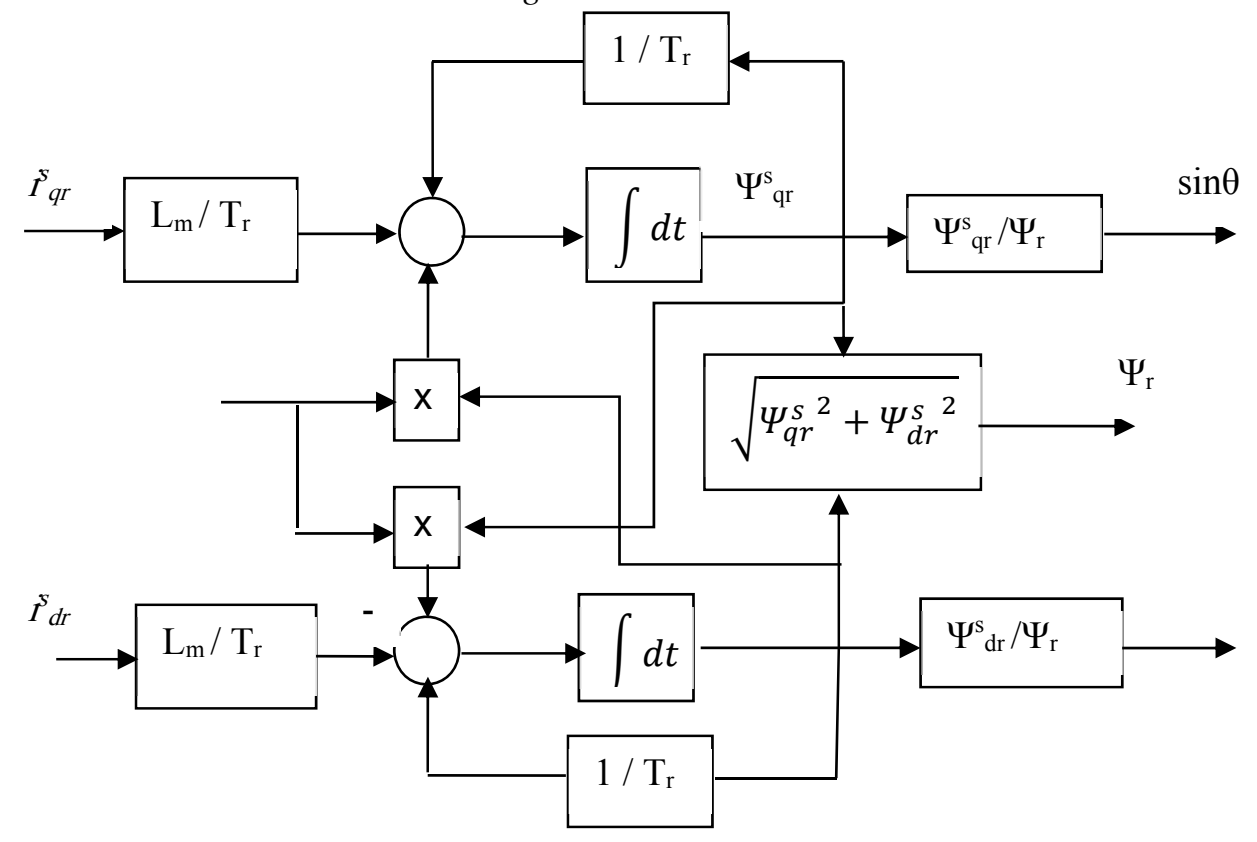

FIG. 3. CURRENT MODEL OF FLUX ESTIMATION

\section{PI CONTROLLER BACKGROUND}

Proportional-Integral (PI) controller has been extensively used in manufacturing due to simple application, low cost and the capability to apply in a widespread series of applications. It also develops the dynamic reaction of the system as well as decreases or eliminates the steady state error and the error susceptibility[10]. Proportional integral controller (PI) contains two components of proportional gain $\left(\mathrm{K}_{\mathrm{p}}\right)$ and integral gain $\left(\mathrm{K}_{\mathrm{i}}\right)$ parts. This controller put in feed forward path of closed loop of the system. Proportional gain is to establish the system stability and to improve transient response. Integral part is to reduce the steady state error. PI controller has the general form:

$$
u(t)=K_{p} e(t)+K_{i} \int_{0}^{t} e(t) d t
$$

Where, $u(t)$ is the output of the PI controller and $e(t)$ is the error signal. Consistently, the transfer function in Laplace domain of the PI controller is:

$$
U(s)=K_{p}+K_{i} / s
$$

Error! Reference source not found. (4) shows the simplified block diagram of the PI controller. 


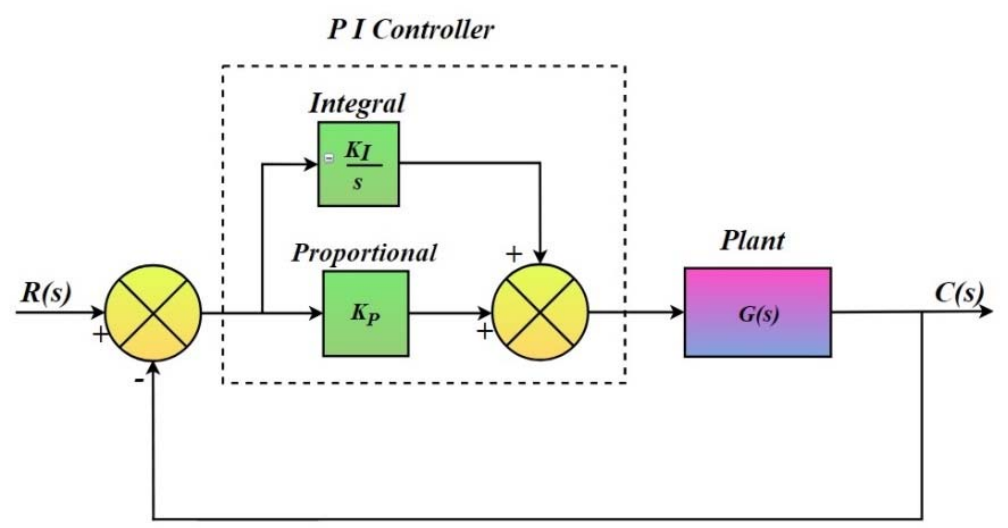

FIG. 4. BLOCK DIAGRAM OF THE PI CONTROLLER

\section{IP CONTROLLER BACKGROUND}

Integral proportional controller is an advanced form of the proportional integral controller. In this controller, the integral part is in the feedforward path and the proportional part is in the feedback path. The disadvantage in the PI controller is the high peak overshoot. To improve the dynamic performance for transient state and reduce that peak overshoot considerably, we can use this IP controller. Fig. (5) shows the simplified block diagram of the integral plus proportional controller.

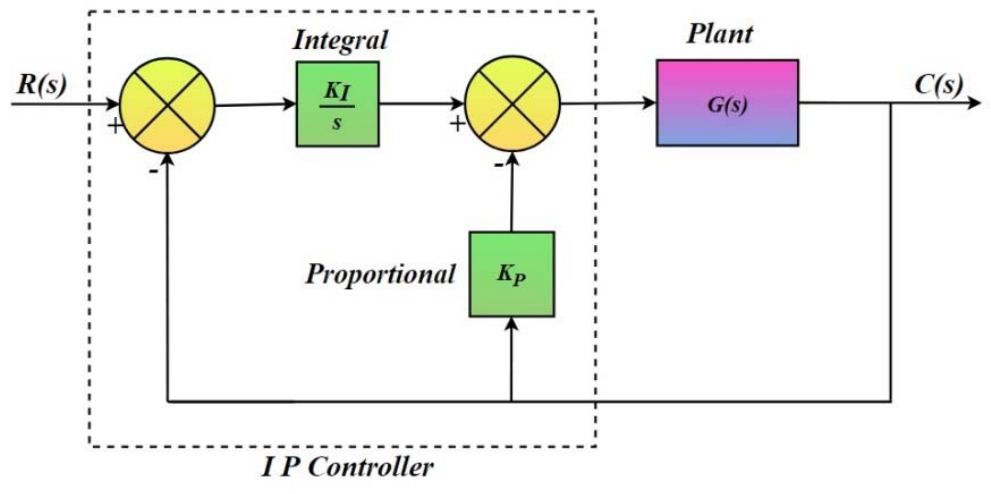

FIG. 5 . BLOCK DIAGRAM OF THE IP CONTROLLER.

$$
\frac{C(s)}{R(s)}=\frac{K_{I} G(s)}{s\left(1+K_{P} G(s)\right)+K_{I} G(s)}
$$

Where

$G(s)=$ Transfer function of plant

$K_{I}=$ Integral gain

$K_{P}=$ Proportional gain

\section{PARTICLE SWARM OPTIMIZATION (PSO)}

The PSO is a powerful method in resolving problems involving non-linearity and non-variation, that result from the social-psychological behavior [10]. It was encouraged through the collective performance of bird flow and fish education, it was found to be powerful in resolving persistent nonlinear improvement difficulties. PSO attracted the attention these days because of its effortlessness and comfort in appliance [9].

In PSO, every one resolution is a "bird" in the exploration area; this is mentioned to be a "particle". The group is designed as particles in a multidimensional space as particles in a 
multidimensional space, with locations and velocities. These particles have two essential abilities: memories for the best location besides the best information of the best global site. Associates of the swarm transfer worthy locations to each other and regulate their locations and speeds on worthy sites. Particles are updated according to the following equations ( 9 and 10).

$$
\begin{gathered}
\mathrm{v}(\mathrm{k}+1)_{\mathrm{i}, \mathrm{j}}=\mathrm{w} \cdot \mathrm{v}(\mathrm{k})_{\mathrm{i}, \mathrm{j}}+\mathrm{c}_{1} \mathrm{r}_{1}\left(\text { gbest }-\mathrm{x}(\mathrm{k})_{\mathrm{i}, \mathrm{j}}\right)+\mathrm{c}_{2} \mathrm{r}_{2}\left(\text { pbest }_{\mathrm{j}}-\mathrm{x}(\mathrm{k})_{\mathrm{i}, \mathrm{j}}\right) \\
\mathrm{x}(\mathrm{k}+1)_{\mathrm{i}, \mathrm{j}}=\mathrm{x}(\mathrm{k})_{\mathrm{i}, \mathrm{j}}+\mathrm{v}(\mathrm{k})_{\mathrm{i}, \mathrm{j}}
\end{gathered}
$$

where,

$v i, j$ : velocity of particle $\mathrm{i}$ and dimension $\mathrm{j}$.

$x i, j:$ position of particle $i$ and dimension $j$.

$\mathrm{c}_{1}, \mathrm{c}_{2}$ : known as acceleration constants.

$\mathrm{w}$ : inertia weight factor.

$\mathrm{r}_{1}, \mathrm{r}_{2}:$ random numbers between 0 and 1 .

pbest: the best position of a specific particle.

gbest: the best particle position of the group.

\section{PSO-PI CONTROLLER PERFORMANCE CRITERIA}

In most intelligent optimization algorithms, public presentation standards include (IAE), (ISE), and (ITSE). This is calculated analytically in the frequency band. Presentation criteria include, overshoot, elevation time, settling time and steady-state error. In addition, it has been identified as an optimized, power-driven system. It is a formula for performance criteria as follows [10]:

$$
\begin{aligned}
& \text { Integral Square Error (ISE) }=\int_{0}^{\infty} \mathrm{e}^{2}(\mathrm{t}) \cdot \mathrm{dt} \\
& \text { Integral Absolute Error (IAE) }=\int_{0}^{\infty}|\mathrm{e}(\mathrm{t})| \cdot \mathrm{dt} \\
& \text { Integral Time Square Error (ITSE) }=\int_{0}^{\infty} \mathrm{t} \cdot \mathrm{e}^{2}(\mathrm{t}) \cdot \mathrm{dt}
\end{aligned}
$$

(ITSE) time domain criterion is used in this work as a "fitness function" for evaluating the PI controller performance. Good controller factors $\left(\mathrm{K}_{\mathrm{p}}, \mathrm{K}_{\mathrm{i}}\right)$ result in worthy results in performance criteria minimization.

\section{SIMULATION AND RESULTS}

MATLAB/Simulink has been used to evaluate the perofmance of the proposed two controller schemes. The practical voltage and the motor speed are the inputs to the Simulink model. Afterward, the model computes the IM stator current, stator flux, rotor current, rotor flux, and IM torque. All the designed parameters of IM that are used in the Simulink model are illustrated in the Appendix. Fig.s (6 and 7) show MATLAB/ Simuink circuit of FOC with PI controller and IP based on PSO controller, respectively.

In this work, ITSE performance index has been used for the PSO tuning method. The PSO parameters that give grander result are listed in Table I.

Responses of the speed and torque for FOC PI-controller and IP controller are tuned by PSO technique at different loads and speeds conditions. Where the selected speeds are $(3000,1500$, and 500) r.p.m., while the load torques are $(0,0.5$, and 1$)$ N.m. The obtained gains of PI for FOC are $\left(\mathrm{kp}=.7287, \mathrm{k}_{\mathrm{i}}=4.0743\right)$ for flux controller, $\left(\mathrm{k}_{\mathrm{p}}=3.3665, \mathrm{k}_{\mathrm{i}}=2.4073\right)$ for torque controller. For IP controller they are $(\mathrm{kp}=$ $0.98, \mathrm{ki}=7.1201)$ for flux controller and $(\mathrm{kp}=0.05, \mathrm{ki}=3.103)$ for torque controller.

Fig.s $(8,9$, and 10) show the speed response for selected values of speed for no load at $(0.0-0.8)$ second, 0.5 N.m. at $(0.8-1.2)$ second and full load of 1 N.m. at $(1.2-2)$ second. 


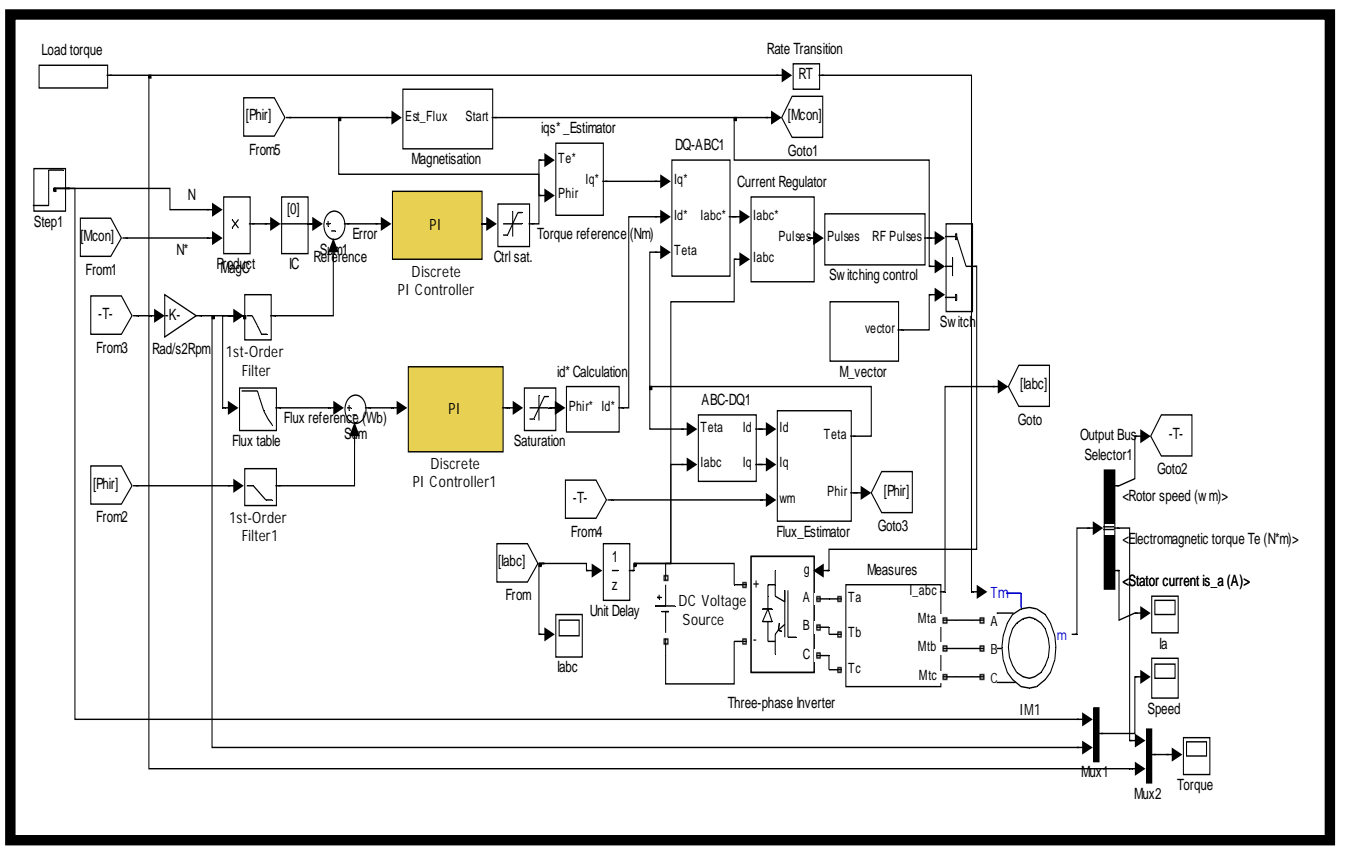

FIG. 6 . FOC WITH PI CONTROLLER MATLAB/SIMULINK CIRCUIT

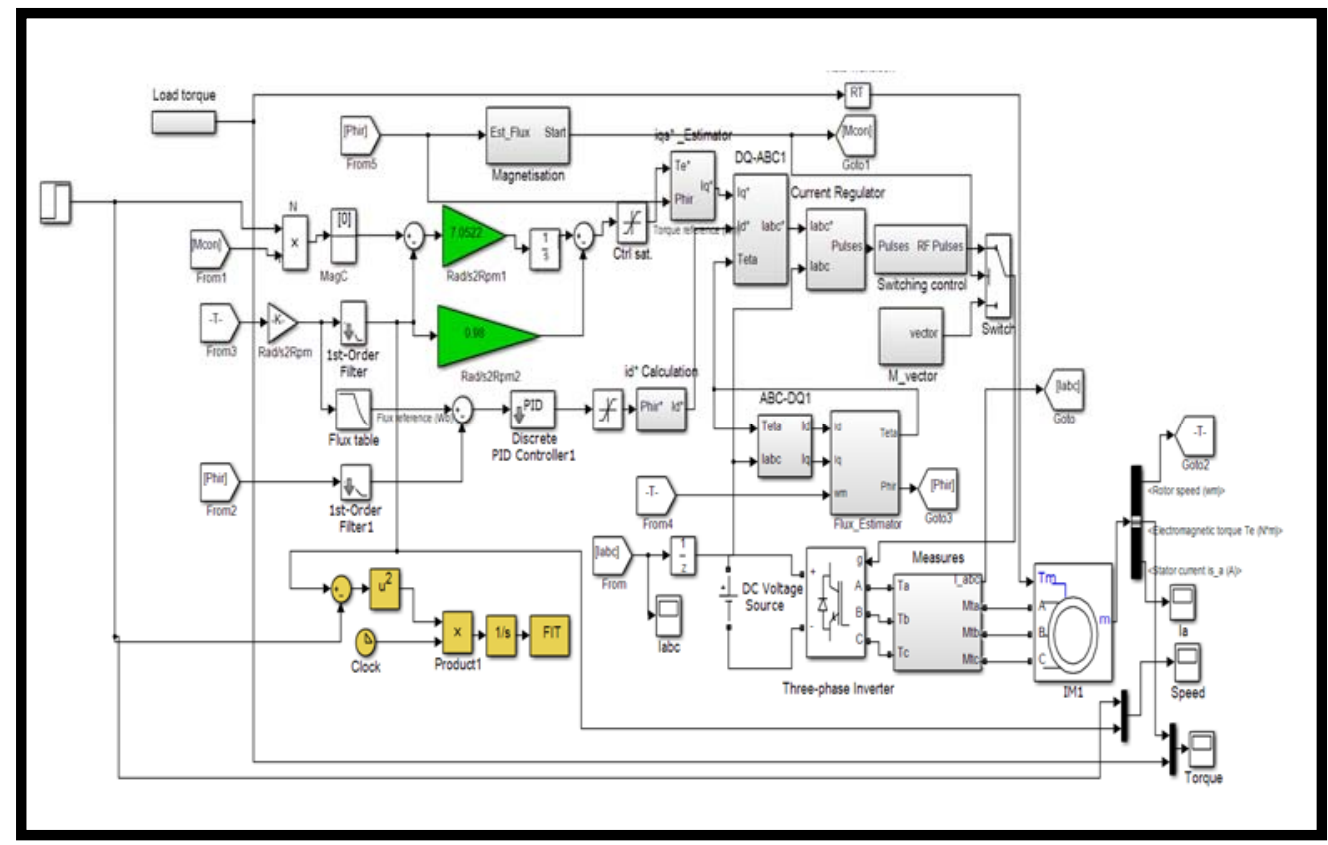

FIG. 7 . SIMULINK BLOCK DIAGRAM FOR I-P CONTROLLER FOR FOC

TABLE I: PSO PARAMETERS

\begin{tabular}{cc}
\hline Swarm size (Number of birds) & 10 \\
Number of iterations & 50 \\
Cognitive coefficient $\left(\mathrm{C}_{1}\right)$ & 1.2 \\
Social coefficient $\left(\mathrm{C}_{2}\right)$ & 1.2 \\
Inertia weight $(\mathrm{w})$ & 0.9 \\
Swarm size (Number of birds) & 10 \\
\hline
\end{tabular}



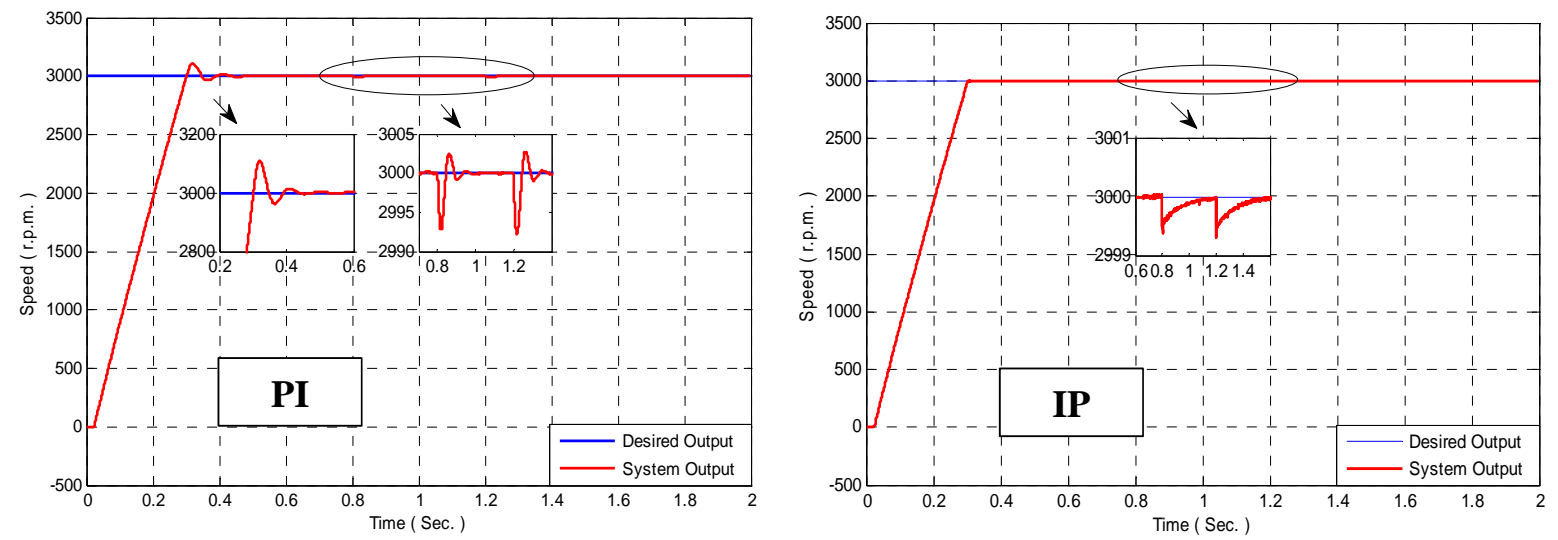

FIG. 8 . SPEED RESPONSE FOR N=3000 R.P.M.
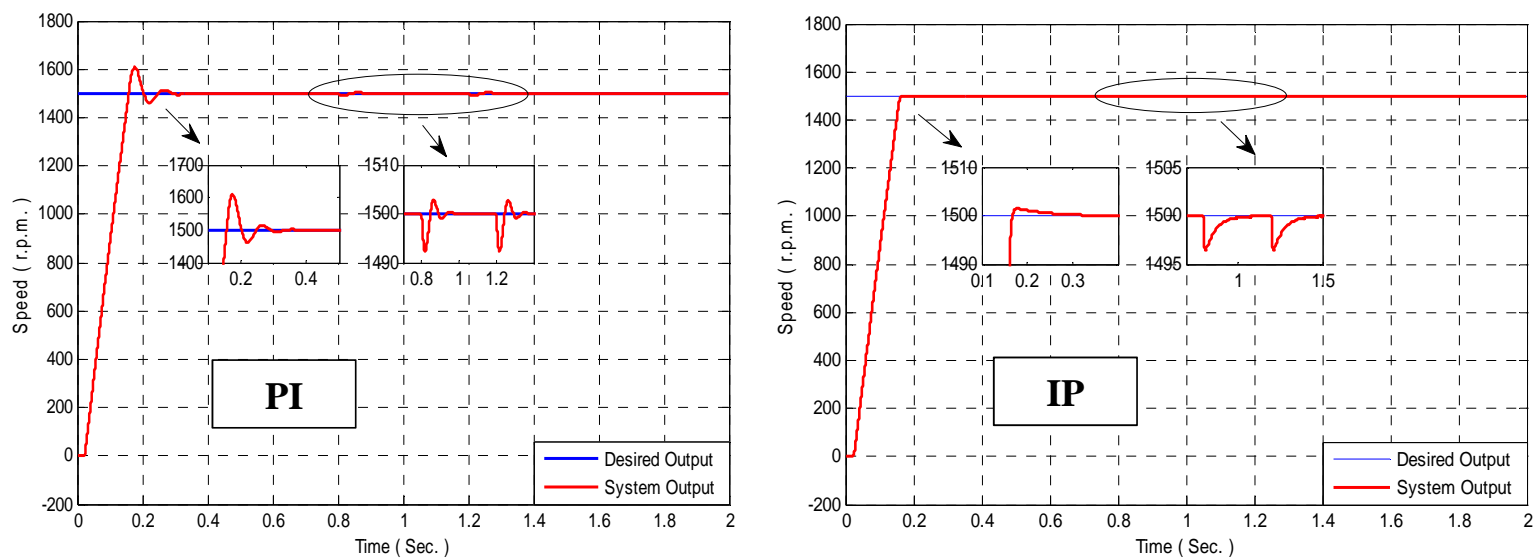

FIG. 9 . SPEED RESPONSE FOR N = 1500 R.P.M.
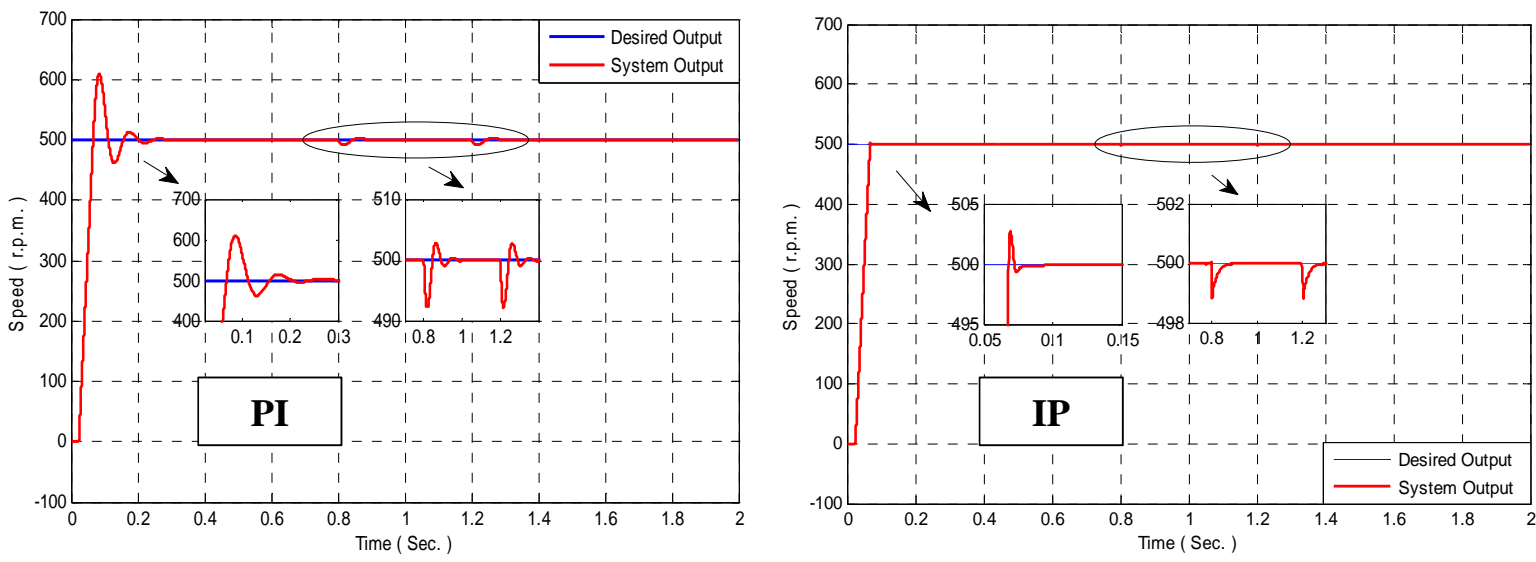

FIG. 10 . SPEED RESPONSE FOR N=500 R.P.M.

The speed response for the PI shows that the overshoots are $(4 \%, 6.3 \%$, and $31 \%)$ and undershoots at applied loads are $(0.27 \%, 0.54 \%$, and $1.58 \%)$ while for the IP controller, the overshoots are $(0.013 \%, 0.053 \%$, and $0.24 \%)$ and undershoots are $(0.03 \%, 0.06 \%$, and $0.18 \%)$. The settling time of PI controller is $(0.71 \%, 0.63 \%$, and $0.51 \%)$ while for the IP controller they are $(0.42 \%, 0.29 \%$, and $0.115 \%)$.

Fig.s (11, 12 and 13) show the electromagnetic torque response for selected speed values for no load at $(0.0-0.8)$ second, 0.5 N.m. at ( $0.8-1.2)$ second and full load of 1 N.m. at $(1.2-2)$ secod . The starting torque for PI controller equals (7.43, 7.13, and 7.13) N.m, respectively for selected 
speeds, while for the IP controller they are (7.1, 7.1, and 7) N.m.
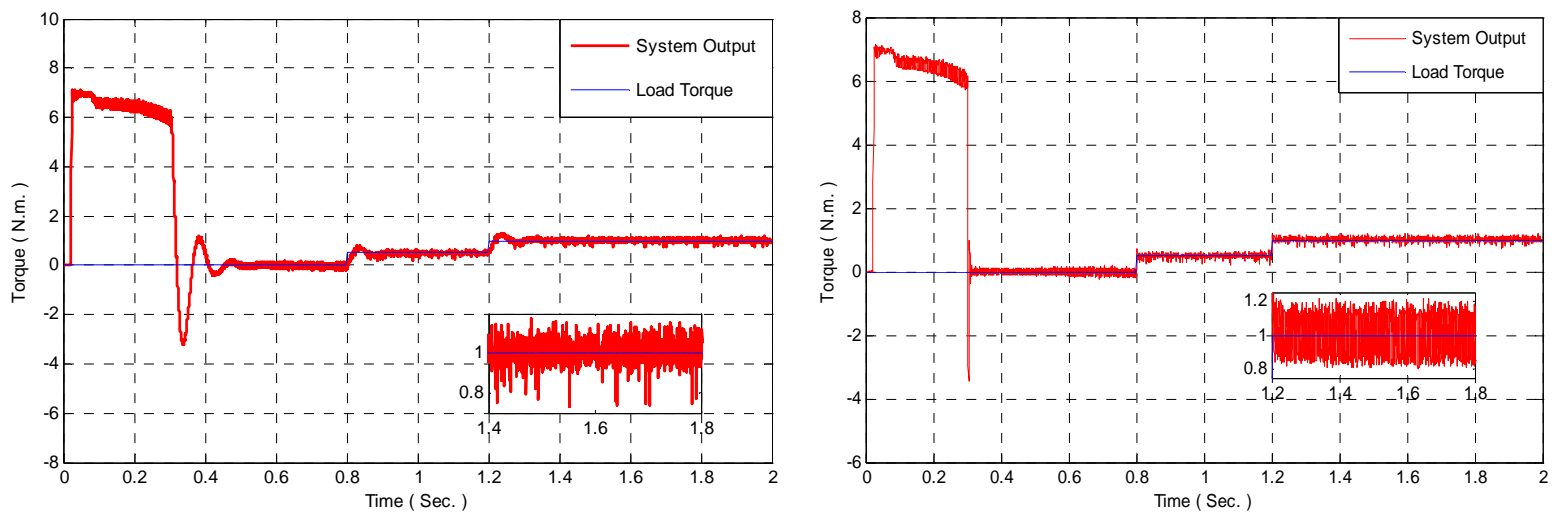

FIG. 11 . ELECTROMAGNETIC TORQUE RESPONSE AT N=3000 R.P.M.
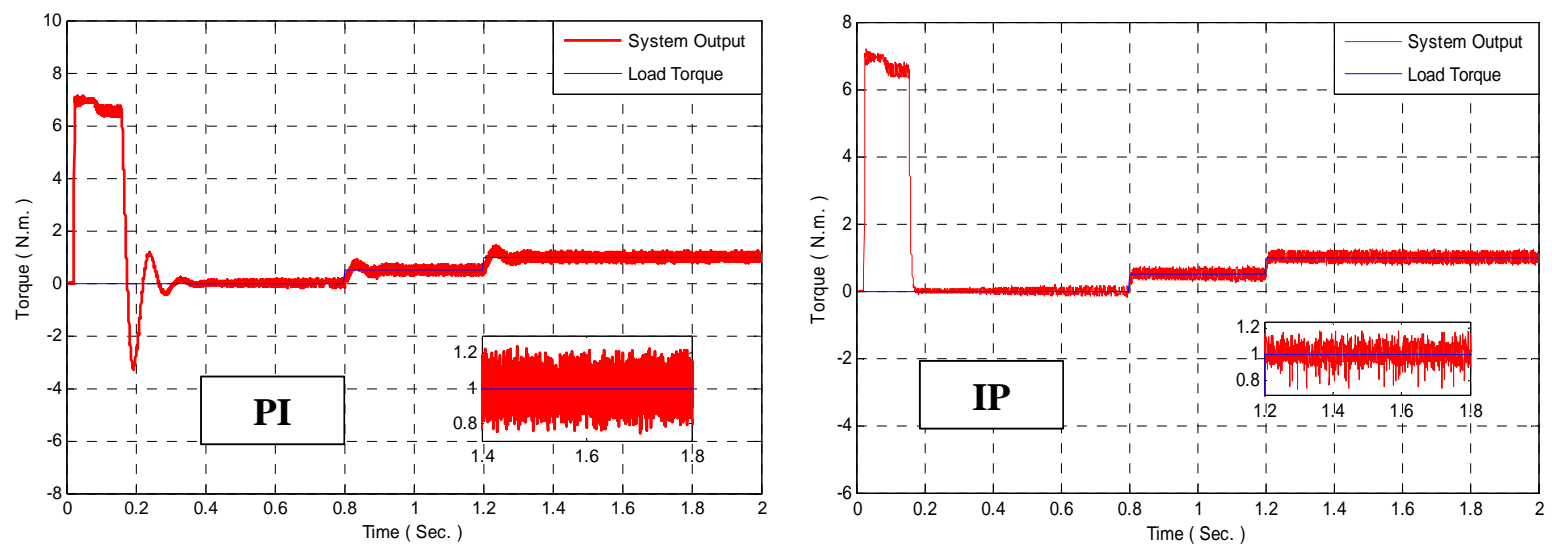

FIG.12. ELECTROMAGNETIC TORQUE RESPONSE AT N = 1500 R.P.M.
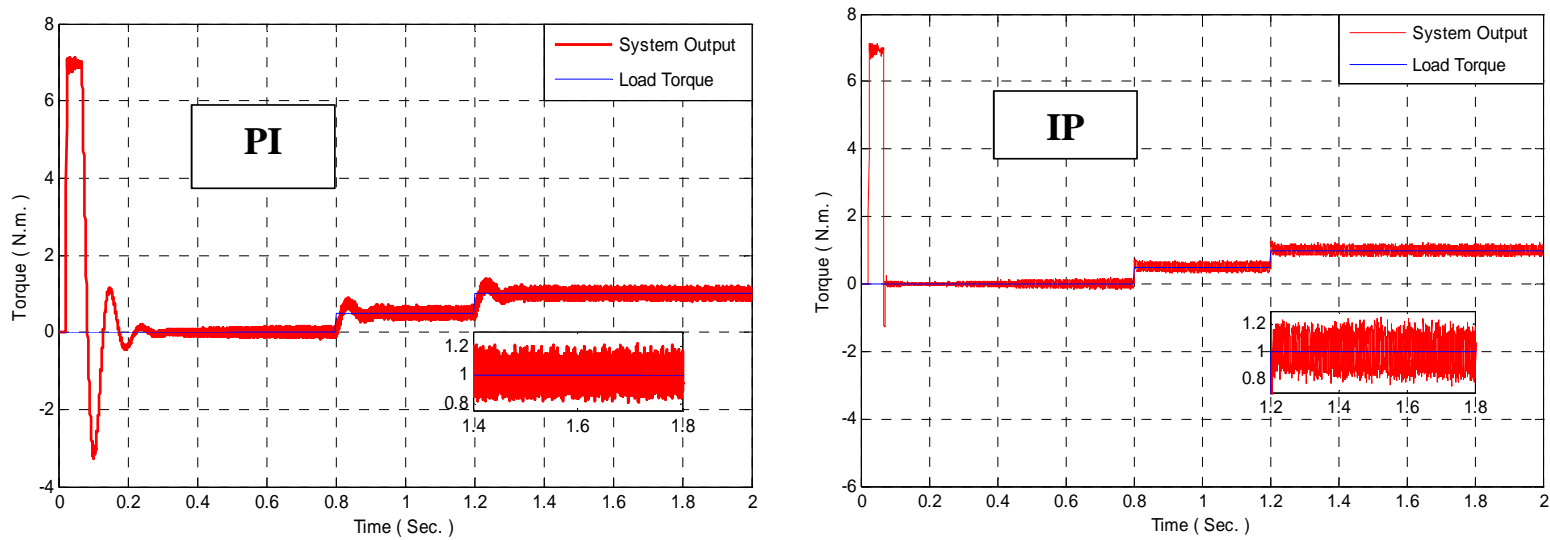

FIG. 13. ELECTROMAGNETIC TORQUE RESPONSE AT N = 500 R.P.M.

Fig.s $(14,15$, and 16) show the three phase current response for selected speed values for no load at $(0.0-0.8)$ second, $0.5 \mathrm{~N} . \mathrm{m}$. at $(0.8-1.2)$ second and $1 \mathrm{~N} . \mathrm{m}$. at $(1.2-2)$ second. The starting torque for FOC equals $(7.3,7.2$, and 5.3) N.m, respectively for the selected speeds. 

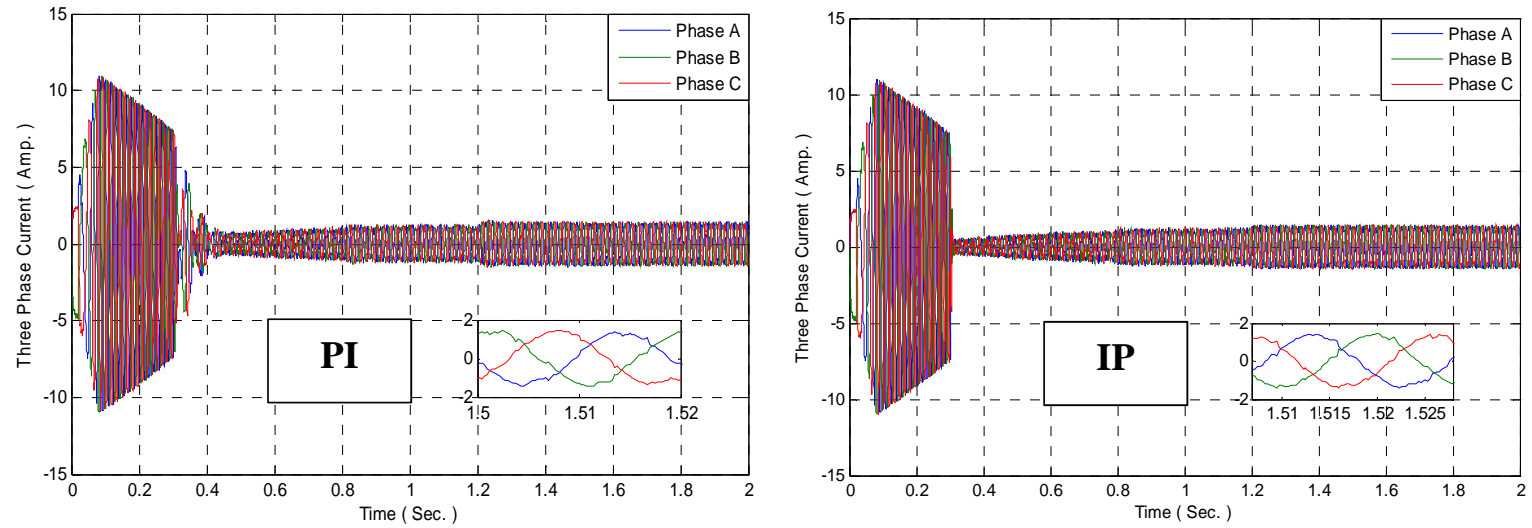

FIG. 14. THREE PHASE CURRENT RESPONSE AT N $=3000$ R.P.M.
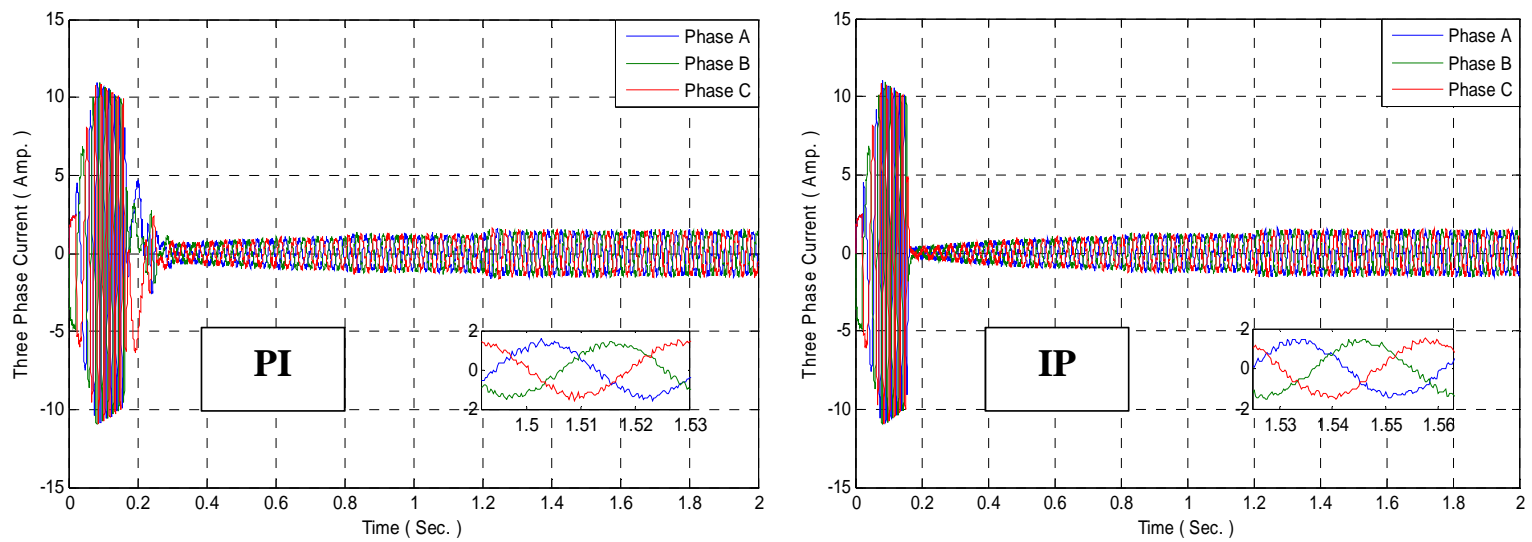

FIG. 15. THREE PHASE CURRENT RESPONSE AT N = 1500 R.P.M.
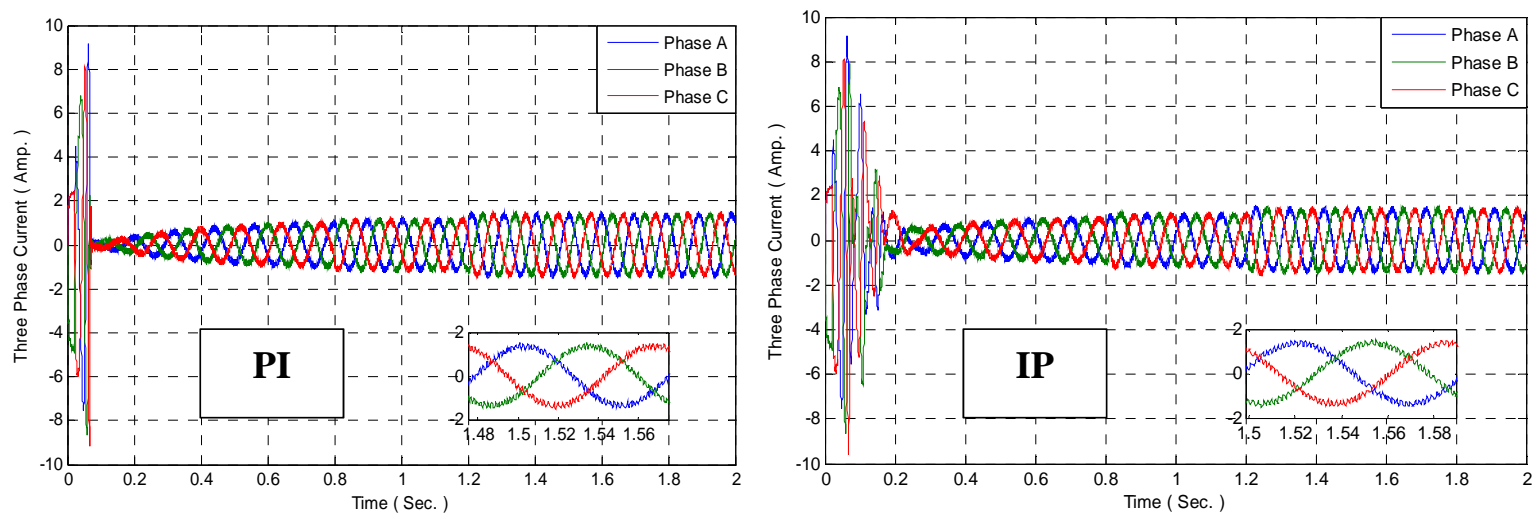

FIG. 16. THREE PHASE CURRENT RESPONSE AT N = 500 R.P.M.

\section{DISCUSSION}

From the comparative simulation results, one can conclude that the two controllers demonstrate nearly the same performances under nominal condition. However, it is observed that the IP controller provides important advantages over the traditional PI controller like limiting the overshoot in speed, thus the starting current overshoot can be reduced. From the comparison, the speeds for both models at steady state follow the desired speed with zero error until the motor is loaded with step torque at $(0.8)$ second, the deviation of the speed due to the load for IP controller is less than PI controller and the speed return to the desired speed is faster. The settling time and the starting torque for the I-P controller are less than those of the PI controller. 


\section{CONCLUSION}

This paper presents a comparison between two controllers; (PI) and (IP) control methods of field oriented control of (IM) drive. The descriptions of these control schemes and their principle of operation have been presented. It can be shown from the speed response that the overshot in the P-I controller is high, while in the IP controller it is reduced. Simulation results show that the proposed IP controller strategy scheme shows better performance than the PI controller strategy.

\section{REFERENCES}

[1] S. K. Pillai, A first course on electrical drives. New Age International, 1990.

[2] K. Bimal, Modern power electronics and AC drives. Prentice-Hall, 2001.

[3] Q. L. Hamdi, Design of Indirect Field-Oriented PWM Inverter for Three-Phase Induction Motor. PhD thesis, Ph.D. Thesis, AlRasheed collage of engineering, University of Technology, 2007.

[4] F. A. Hassan "Field Oriented Control for Three Phase Induction Motor Based On Full Neural Estimator and Controller" Engineering and Technology Journal,, vol. 28, no.15, 2010.

[5] A. T. Humod , M. N. Abdullah , F. H. Faris "A Comparative Study between Vector Control and Direct Torque Control of Induction Motor Using Optimal Controller” International Journal of Scientific \& Engineering Research, vol. 7, Issue 4, April-2016.

[6] P. Kumar B., M. Kumar B., A. Kumar S., " Comparative Analysis of scalar \& vector control of Induction motor through Modeling \&Simulation " , International Journal Of Innovative Research In Electrical, Electronics, Instrumentation And Control Engineering vol. 2, Issue 4, April 2014.

[7] A. T. Humod, M. N. Abdullah, F. H. Faris, "Field Oriented Control of Three Phase Induction Motor Based on Fractional Order PI-Controller Using Particle Swarm Optimization Technique, Advances in Natural and Applied Sciences; Pages: 9-20, ISSN: 1995-0772, November 2017.

[8] S. K. Pillai, A first course on electrical drives. New Age International, 1990.

[9] Y. Y.-W. Klop and M. M.-P. Nijdam, "Tuning a PID controller: Particle Swarm Optimization versus Genetic Algorithms," ed: February, 2010.

[10] F. A. Hassan and L. J. Rashad, "Particle swarm optimization for adapting fuzzy logic controller of spwm inverter fed 3phase IM," Engineering and Technology Journal, vol. 29, no. 14, pp. 2912-2925, 2011.

Induction motor data

\section{Appendix}

\begin{tabular}{|l|l|}
\hline Rated power & $300 \mathrm{~W}$ \\
\hline Rated voltage & $380 \mathrm{~V}$ \\
\hline Rated frequency & $50 \mathrm{~Hz}$ \\
\hline Rated speed & $3000 \mathrm{rpm}$ \\
\hline Number of poles & 2 \\
\hline Stator resistance & $\mathrm{Rs}=15.3 \Omega$ \\
\hline Stator inductance & $\mathrm{Ls}=0.038 \mathrm{H}$ \\
\hline Rotor resistance & $\mathrm{Rr}=11.7 \Omega$ \\
\hline Rotor inductance & $\mathrm{Lr}=0.0288 \mathrm{H}$ \\
\hline Mutual inductance & $\mathrm{Lm}=0.75 \mathrm{H}$ \\
\hline Moment of inertia & $0.0173 \mathrm{Kg} . \mathrm{m}^{2} / \mathrm{sec}$ \\
\hline
\end{tabular}

